\title{
MODELAGEM MATEMÁTICA NUM CURSO DE GESTÃO FINANCEIRA: RELATO E REFLEXÕES SOBRE O TRABALHO EM GRUPO
}

\section{MATHEMATICAL MODELING IN A FINANCIAL MANAGEMENT COURSE: REPORT AND REFLECTIONS ABOUT THE GROUP WORK}

\author{
Daniel Zampieri Loureiro ${ }^{1}$ \\ Rodolfo Eduardo Vertuan ${ }^{2}$ \\ Tiago Emanuel Klüber ${ }^{3}$
}

\begin{abstract}
Resumo: Este relato busca discutir uma atividade desenvolvida no contexto de um curso de graduação que tratou do planejamento orçamentário familiar desenvolvido por alunos do Curso de Gestão Financeira em um contexto da Modelagem Matemática. Focamos, no desenvolver do relato, nos elementos que decorrem do trabalho dos grupos de alunos, a luz da interrogação: o que se mostra dos grupos de alunos em uma atividade de Modelagem Matemática? Dentre os elementos postos analisados, destacam-se aqueles que dizem do conteúdo de estatística utilizado pelos alunos, da postura dos alunos no interior dos grupos, da postura docente e das estratégias para resolução.
\end{abstract}

Palavras-chave: Prática Docente; Tendência em Educação Matemática; Modelagem Matemática aplicada à Estatística.

\begin{abstract}
This report seeks to discuss an activity developed in the context of an undergraduate course which treated on the family budget planning developed by students of the Financial Management Course in a context of Mathematical Modeling. We focus, in the development of the report, on the elements that derive from the work of the groups of students, under the question: what shown of the groups of students in a Mathematical Modeling activity? Among the elements ananalized, it is emphasized those that say the content of statistics used by the students, the posture of the students within the groups, the teaching posture and the strategies for resolution.
\end{abstract}

Keywords: Teaching Practice; Trend in Mathematics Education; Mathematical Modeling applied to Statistics.

\footnotetext{
${ }^{1}$ Doutorando do Programa de Pós-Graduação em Educação em Ciências e Educação Matemática pela Universidade Estadual do Oeste do Paraná (UNIOESTE). Professor do Centro Universitário UNIVEL, Cascavel, Paraná, Brasil. E-mail: zampiieri@ hotmail.com

${ }^{2}$ Doutor em Ensino de Ciências e Educação Matemática pela Universidade Estadual de Londrina (UEL). Professor da Universidade Tecnológica Federal do Paraná (UTFPR), Toledo, Paraná, Brasil. E-mail: rodolfovertuan@yahoo.com.br

${ }^{3}$ Doutor em Educação Científica e Tecnológica pela Universidade Federal de Santa Catarina (UFSC). Professor da Universidade Estadual do Oeste do Paraná (UNIOESTE), Cascavel, Paraná, Brasil. E-mail: tiagokluber@gmail.com
} 
DOI: http://dx.doi.org/10.33238/ReBECEM.2019.v.3.n.1.22029

\section{Contextualizando a experiência}

Antes de apresentarmos nossa experiência propriamente dita, elucidar a ideia do contexto no qual emerge a proposta de nossa atividade se faz necessário, no intuito de iluminar a compressão do leitor sobre o caminho que percorrerá no decorrer do texto.

Nossa inquietação se revela na participação de uma disciplina denominada Modelagem Matemática na Educação Matemática, vinculada ao Programa de PósGraduação em Educação em Ciências e Educação Matemática da Universidade Estadual do Oeste do Paraná - Unioeste. A disciplina mencionada aconteceu no segundo semestre de 2017, com encontros semanais, tendo carga horária prevista de 60 horas, com uma subdivisão de 30 horas práticas e 30 horas teóricas. Porém, vale mencionar que a apresentação da disciplina aos acadêmicos da pós-graduação - mestrado e doutorado -, aconteceu na relação prática e teoria que dizia da Modelagem Matemática na Educação Matemática, ou seja, em muitos momentos, prática e teoria aconteciam de forma concomitante, proporcionando a construção mais dinâmica do conhecimento no que tange à tendência em questão, não necessitando de um momento específico para um ou outro acontecer.

$\mathrm{Na}$ disciplina foram desenvolvidas práticas de Modelagem, que puderam aproximar aqueles que ainda não haviam tido contato com ela, propiciando trocar experiências e criar "portfólios" para experiências futuras. Além das práticas de modelagem foram desenvolvidas ainda análises de artigos científicos, debates e mesas redondas.

Ressaltamos que o docente responsável pela disciplina, é doutor na área Ensino, com tese em Modelagem Matemática na Educação Matemática, além disso, é membro ativo na comunidade acadêmica de Modelagem. Destacamos tal fato considerando o impacto positivo que um professor com relevante conhecimento na área pode causar na formação dos discentes, já que este possui conhecimento de teoria e prática nos diferentes contextos da educação, seja Básica ou Superior, principalmente no que diz respeito ao papel de orientador das atividades desenvolvidas. Em certo sentido, isso contribui para que os acadêmicos não fiquem aficionados ingenuamente a uma "[...] concepção prévia de Modelagem Matemática na Educação Matemática, deixando de incentivar novas abordagens" (LOUREIRO, 2016, p. 115), ou seja, os alunos têm a possibilidade de construir um conhecimento significativo, replicando e reinventando abordagens a partir 


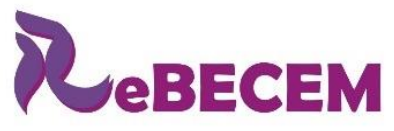

DOI: http://dx.doi.org/10.33238/ReBECEM.2019.v.3.n.1.22029

Revista Brasileira de Educação em

Ciências e Educação Matemática

ISSN 2594-9179

daquilo que foi estudado. Desta maneira, a influência do professor formador incide de modo indireto/direto nas propostas desenvolvidas no cerne da disciplina.

Neste contexto, como trabalho final, foi solicitado pelo docente o desenvolvimento de uma atividade "inédita" ou a reinterpretação de uma atividade já desenvolvida, uma vez que dos resultados de uma atividade de Modelagem ${ }^{4}$ já aplicada podem emergir novas interpretações.

Esse trabalho final consistia, portanto, na elaboração de um relato para a obtenção de créditos a disciplina. Contudo, indo além do mero cumprimento das exigências formais, assumindo a postura de pesquisadores e membros do grupo de pesquisa "Formação de Professores de Ciências e Matemática - FOPECIM" da Unioeste na linha de pesquisa "Modelagem Matemática na Educação Matemática e Formação de Professores" no qual estamos vinculados, buscaremos lançar luz a interrogação: $o$ que se mostra dos grupos de alunos em uma atividade de Modelagem Matemática? Além disso, vislumbramos abrir discussões sempre que possível no interior do próprio grupo de pesquisa, ou a partir de participações em eventos e publicações em periódicos, visando fortalecer nossa própria experiência como docentes e contribuir com aqueles que intencionam desenvolver práticas no âmbito da Modelagem Matemática na Educação Matemática.

\section{Sobre Modelagem Matemática: um breve apanhado}

A Modelagem Matemática tem se mostrado uma tendência que pouco a pouco tem angariado adeptos, independentemente do nível de ensino sobre o qual lançamos nosso olhar, seja na Educação Básica, Ensino Médio, Ensino Superior.

A partir das pesquisas emergentes, nota-se uma diversidade de eventos ganhando notoriedade, abordando diretamente a temática Modelagem Matemática, como: 1) Encontro Paranaense de Modelagem Matemática na Educação Matemática - EPMEM; e 2) Conferência Nacional sobre Modelagem na Educação Matemática - CNMEM., 3) Conferência Internacional de Modelagem e Aplicações Matemática no Ensino - ICTMA. Quanto ao exposto, podemos fazer menção a eventos que trazem em seu escopo a temática mencionada como eixo de trabalho e divulgação de pesquisa: 4) Encontro Nacional de Educação Matemática - ENEM; 5) Seminário Internacional de Pesquisa em Educação

\footnotetext{
${ }^{4}$ Para leitura entenda-se Modelagem como Modelagem Matemática na Educação Matemática.
} 
DOI: http://dx.doi.org/10.33238/ReBECEM.2019.v.3.n.1.22029

Matemática - SIPEM; 6) Conferência Interamericana de Educação Matemática - CIAEM

e 7) semanas acadêmicas promovidas por instituições de nível superior em todo território nacional.

A realização dos eventos em âmbito nacional e internacional permite a autores ganharem destaque, pela relevância, continuidade e abrangência de seus trabalhos. Ao encontro disso, Loureiro (2016) ao efetuar um levantamento das obras de referência em Modelagem Matemática mais utilizadas na esfera educacional, destaca que diferentes concepções insurgem em nosso país e além disso demarcam, tanto prática, como teoricamente, "[...] o "universo" da Modelagem Matemática no que diz respeito ao cenário nacional" (LOUREIRO, 2016, p. 60), como por exemplo as de autores como 1) Ademir Donizeti Caldeira, 2) Dionísio Burak, 3) Jonei Cerqueira Barbosa, 4) Lourdes Maria Werle Almeida e 5) Maria Salett Biembengut, entre outros que poderíamos nomear.

Neste contexto, apresentamos as mencionadas em (KLÜBER; BURAK, 2008, p. 31) no quadro 1 a seguir, considerando que são as mais conhecidas e citadas no âmbito da Modelagem Matemática na Educação Matemática brasileira.

\begin{tabular}{|c|c|}
\hline Autores & Concepção de Modelagem \\
\hline Barbosa & $\begin{array}{l}\text { "Modelagem é um ambiente de aprendizagem no qual os alunos são convidados } \\
\text { a indagar e/ou investigar, por meio da matemática, situações oriundas de outras } \\
\text { áreas da realidade." }\end{array}$ \\
\hline Biembengut & "processo que envolve a obtenção de um modelo." \\
\hline Burak & $\begin{array}{l}\text { "conjunto de procedimentos cujo objetivo é construir um paralelo para tentar } \\
\text { explicar, matematicamente, os fenômenos presentes no cotidiano do ser humano, } \\
\text { ajudando-o a fazer predições e a tomar decisões." }\end{array}$ \\
\hline Caldeira & $\begin{array}{l}\text { Concepção de Educação Matemática, constituindo-se em "um sistema de } \\
\text { aprendizagem". }\end{array}$ \\
\hline
\end{tabular}

Fonte: Concepções de modelagem matemática: contribuições teóricas (KLÜBER; BURAK, 2008, p. 31).

Em outra pesquisa, destacamos que as diversas concepções de Modelagem que emergem de pesquisas registradas na literatura, revelam um arcabouço, no mínimo, consistente, possibilitando àqueles que demonstrarem interesse em desenvolver práticas nessa perspectiva, optar por qualquer uma das concepções, no intuito de prover um ensino dinâmico, reflexivo e significativo (LOUREIRO, 2016). Com esse olhar, passamos ao relato de nossa experiência. 


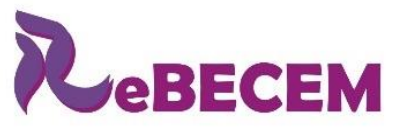

DOI: http://dx.doi.org/10.33238/ReBECEM.2019.v.3.n.1.22029

\section{Sobre a nossa experiência}

Considerando o exposto, e a proposta de atividade no interior da disciplina de do programa de pós-graduação, passamos à reflexão e elaboração da atividade, a qual foi planejada no âmbito da disciplina e posteriormente implementada em uma sala de aula.

A atividade planejada na disciplina deveria ser desenvolvida em uma determinada turma. Optamos por uma atividade dirigida a uma turma do Ensino Superior, na qual o primeiro autor do artigo leciona, mais especificamente em uma turma de segundo semestre de Gestão Financeira, na disciplina de Estatística. A turma em questão foi escolhida pensando na quantidade de aulas disponíveis, no que concerne ao currículo, ou seja, os conteúdos previstos estavam sendo trabalhados sem atrasos ${ }^{5}$, logo não haveria necessidade de pensarmos uma atividade voltada a abordagem desse ou daquele conteúdo em específico, no entanto, devido à atividade ser realizada em uma turma na qual desenvolvia-se um curso de estatística, era razoável que isso delimitasse ao menos o campo da Matemática em que a atividade seria realizada. Além disso, não pretendíamos ficar presos aos conteúdos do currículo, pois compreendemos que tal postura engessa a dinâmica de trabalho proposta pela Modelagem Matemática.

A disciplina de Estatística na qual foi desenvolvida a atividade, possui carga horária de 70 horas semestrais, tendo dois encontros semanais. A turma era composta por 40 alunos matriculados, dos quais 28 efetivamente participaram das atividades. Mencionamos que a atividades desenvolvidas ocorreram seguindo o formato de duas aulas de 50 minutos cada, nas quais foram distribuídos os textos norteadores, e efetuadas as respectivas leituras e formação de grupos e mais 4 aulas de 50 minutos, nas quais ocorreram orientações e pesquisas realizadas pelos alunos

Vale mencionar que a atividade de modelagem se aproxima do caso 2 exposto por Barbosa (2004), considerando que os “[...] alunos deparam-se apenas com o problema para investigar, mas têm que sair da sala de aula para coletar dados. Ao professor, cabe apenas a tarefa de formular o problema inicial" (BARBOSA, 2004, p. 4). Em outras palavras, no entendimento deste autor os alunos passam a ter maior responsabilidade pelo desenvolvimento da atividade, mesmo que essa responsabilidade seja compartilhada com o professor.

\footnotetext{
${ }^{5}$ Considerando o cumprimento do plano de ensino (determinação da Instituição de Nível Superior).
} 
DOI: http://dx.doi.org/10.33238/ReBECEM.2019.v.3.n.1.22029

Em relação ao planejamento da atividade de Modelagem Matemática, considerando que a tendência, permite trazer "[...] para a sala de aula os problemas da vida real e da cultura dos alunos para dialogarem com o conhecimento universal, lógico e válido em todos os tempos e lugares da matemática" (BRANDT; BURAK; KLÜBER, 2010, p.5), buscamos construir com o aluno conhecimento teórico em relação às ações desenvolvidas enquanto Gestor Financeiro, a partir de práticas que se aproximassem da realidade deles.

Nesse sentido, nossa proposta se materializou a partir de fragmentos de um texto ${ }^{6}$ que diz do perfil do gestor financeiro, com o qual buscamos situar os acadêmicos sobre o perfil profissional almejado, relacionado ao curso de graduação em que estão matriculados. A partir do texto propusemos exercitar um pouco das atividades relacionadas à gestão financeira, para tanto, foi sugerido olhar para as nossas próprias despesas e refletir sobre como melhor operacionalizá-las.

Feito isso, um segundo texto apresentava aos alunos um estudo sobre o controle do orçamento familiar ${ }^{7}$, trazendo erros comuns quando se busca realizar tal planejamento.

Figura 1: Parte do texto disparador da problemática

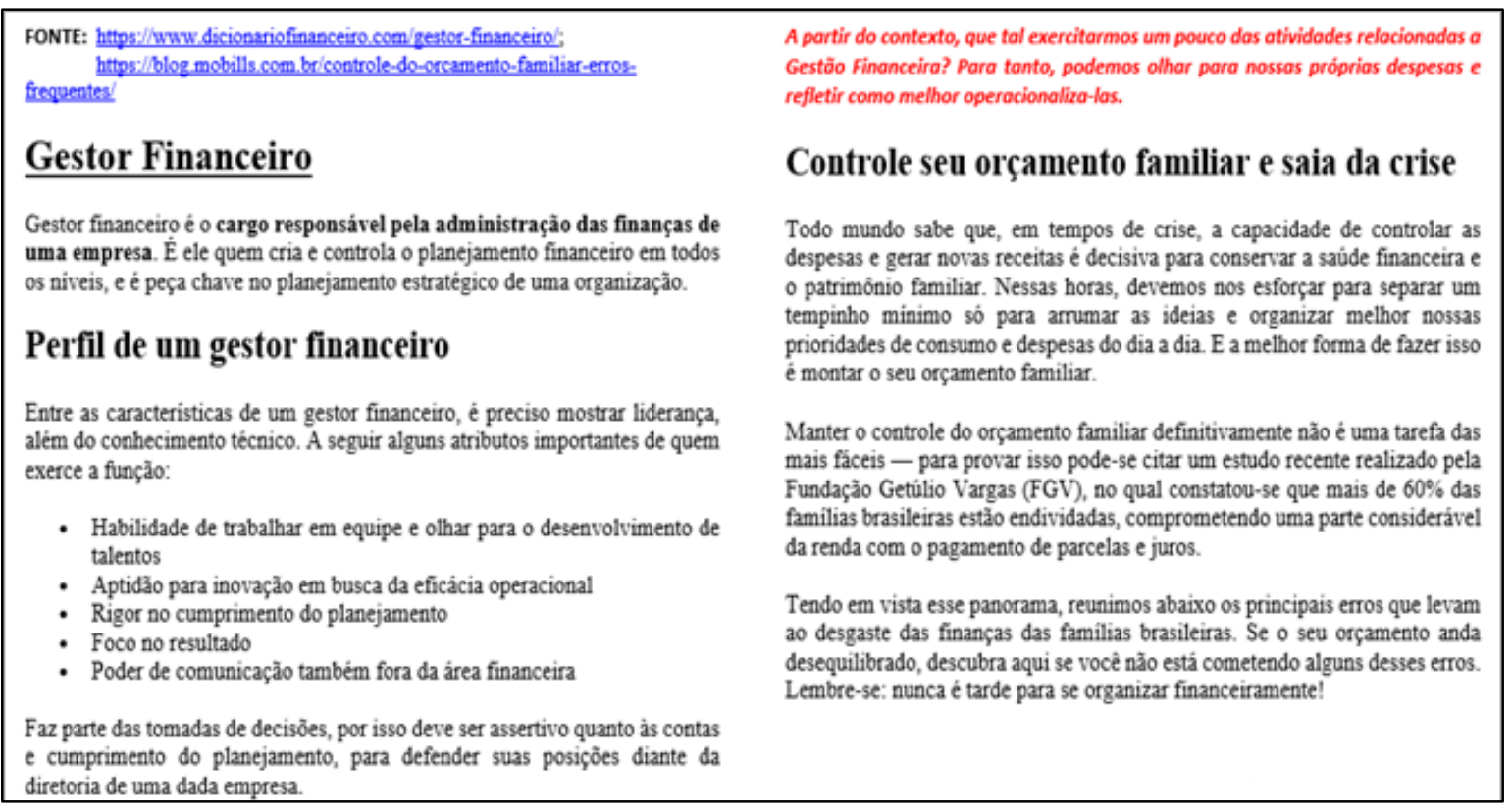

Fonte: Os autores

${ }^{6}$ Retirado de página eletrônica https://www.dicionariofinanceiro.com/gestor-financeiro/. Acesso em 15/11/2017.

7 Retirado de página eletrônica https://blog.mobills.com.br/controle-do-orcamento-familiar-errosfrequentes/. Acesso em 15/11/2017. 


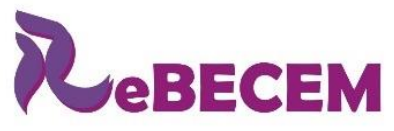

DOI: http://dx.doi.org/10.33238/ReBECEM.2019.v.3.n.1.22029
Revista Brasileira de Educação em

Ciências e Educação Matemática

ISSN 2594-9179

A partir daí, propusemos aos alunos, que em grupos, planejassem seus próprios orçamentos domésticos e, além disso, efetuassem uma previsão dos gastos para daqui a 10 anos.

Tendo realizado as respectivas leituras, os alunos reuniram-se em grupos, contendo de 3 a 5 integrantes, considerando a interação entre os sujeitos, pois, "as interações podem ser entendidas como ações que os indivíduos exercem sobre outros sem que haja, necessariamente, finalidade de transferir informação, mas sim de estabelecer uma relação, um entendimento entre pessoas" (ALMEIDA, 2012, p. 32).

Porém, houve a necessidade de buscar maior aprofundamento sobre os procedimentos para organização do orçamento familiar, considerando que o texto apresentado tinha como propósito apenas provocar a curiosidade dos alunos. No contexto da sala de aula, os alunos utilizaram os recursos tecnológicos como notebook e celulares para realizarem as pesquisas, concernentes ao aprofundamento do tema investigado.

Os alunos exploraram alguns modelos prontos de orçamentos disponíveis na rede, assim, conseguiram dar iniício à sistematização dos seus próprios modelos.

Nos grupos, começaram a organizar os planejamentos orçamentários. Vale mencionar que a elaboração dos planejamentos ficou livre, ou seja, os alunos tiveram liberdade para decidir o modo organizar os dados e o que cada um dos orçamentos conteria, como por exemplo: 1) renda salarial; 2) gastos com alimentação; 3) saúde; 4) lazer; 5) estudos e outros. Ainda, que cada um dos itens citados se subdividem em outros itens os quais os alunos consideraram importante especificar. Por exemplo, no item alimentação, foram listados elementos como "mercado", restaurante, panificadora, doces e salgados em geral e assim por diante, conforme pode ser visto no quadro 02.

Quadro 2: Plano de orçamento doméstico

\begin{tabular}{|c|c|c|c|c|}
\hline \multicolumn{5}{|c|}{ PLANILHA DE ORÇAMENTO DOMÉSTICO } \\
\hline Despesas & $\mathbf{P 0 1}^{8}$ & P02 & P03 & P04 \\
\hline Habitação & & & & \\
\hline Aluguel & & & & \\
\hline Energia Elétrica & & & & \\
\hline Água & & & & \\
\hline TV por assinatu & & & & \\
\hline Telefone & & & & \\
\hline Gás & & & & \\
\hline Saúde & & & & \\
\hline Plano de Saúde & & & & \\
\hline Medicamentos & & & & \\
\hline Dentista & & & & \\
\hline
\end{tabular}

${ }^{8}$ P01 - Participante 01; P02 - Participante 02 e assim sucessivamente. 


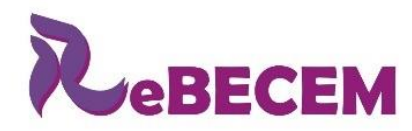

Revista Brasileira de Educação em

Ciências e Educação Matemática

ISSN 2594-9179

DOI: http://dx.doi.org/10.33238/ReBECEM.2019.v.3.n.1.22029

\begin{tabular}{|l|l|l|l|l|}
\hline Alimentação & & & & \\
\hline Restaurantes & & & & \\
\hline Lanchonetes & & & & \\
\hline Supermercado & & & & \\
\hline Transporte & & & & \\
\hline Ônibus & & & & \\
\hline Van & & & & \\
\hline Taxi & & & & \\
\hline Educação & & & & \\
\hline Faculdade & & & & \\
\hline Material Escolar & & & & \\
\hline Xérox & & & & \\
\hline Total & & & & \\
\hline
\end{tabular}

Fonte: Os autores

No interior dos grupos, os alunos decidiram se fariam levantamentos individuais ou levantamentos em grupo de suas respectivas despesas; se esses elementos financeiros corresponderiam a cada integrante individualmente ou à totalidade. Essas decisões refletiram no produto final da atividade, portanto, nas projeções de 10 anos no planejamento orçamentário.

No que concerne à postura docente, vale mencionar, que não se resume a um contato primeiro com modelagem, tendo desenvolvido outras práticas em distintos momentos da sua formação acadêmica e atuação profissional. O professor, como já dito, também é membro de um grupo de pesquisa que dedica-se à investigação da temática em questão. Nesse contexto, consideramos que a apropriação teórica se revela significativa, queremos dizer com isso que, conhecer diferentes concepções de modelagem nos permite um trabalho consistente no que tange à nossa participação no desenvolver da atividade. Assim, buscamos Ànos alinhar a proposta com a do caso 2 de Barbosa (2001).

Nesse sentido, a postura assumida foi de mediador, considerando que após lançada a problemática, os alunos passaram a ser os responsáveis pelas estratégias assumidas para a resolução dela. Ser mediador implica de acordo com Bulgraen (2010) em colocar-se como um elo entre o conhecimento e o aluno, visando que aluno construa por si só os conhecimentos inerentes a determinado conteúdo.

$\mathrm{Na}$ figura de docente, após constituídos os grupos de trabalho, passamos ao estabelecimento de um diálogo com os alunos. Eles, de maneira geral, ficam com dúvidas sobre o modo de desenvolver as atividades; esperam que o professor estabeleça regras para a resolução de exercícios; esperam que lhes sejam indicadas as estratégias que devem utilizar ou qual conteúdo devem utilizar para as resoluções. 
DOI: http://dx.doi.org/10.33238/ReBECEM.2019.v.3.n.1.22029

Além disso, tivemos a preocupação em não anunciar aos alunos que se tratava de uma atividade de Modelagem Matemática, pois consideramos que ela pode ocorrer no desenvolver da aula, sem a necessidade de tal informação, de tal modo que possa ser incorporada de maneira constante, tornando-se familiar aos estudantes.

No diálogo com os grupos, pudemos perceber distintas maneiras de pensar e refletir sobre as estratégias na busca por alternativas para as resoluções. Isso ficou nítido, por exemplo, na maneira como os grupos construíram os planos orçamentários, pois alguns deles foram descritos mês a mês no decorrer de um ano, outros, no decorrer de uma fração de ano, como pode ser observado nas figuras 02, 03 e 04.

Figura 2: modelo de plano orçamentário produzido pelos acadêmicos

\begin{tabular}{|c|c|c|c|c|c|c|c|c|c|c|c|c|c|}
\hline & Janeiro & Fevereiro & Março & Abril & Maio & Junho & Julho & Agosto & Setembro & Outubro & Novembro & Dezembro & TOTAL \\
\hline & $23.804,00$ & $23.804,00$ & $23.804,00$ & $23.804,00$ & $23.804,00$ & $23.804,00$ & $23.804,00$ & $23.804,00$ & $23.804,00$ & $23.804,00$ & $23.804,00$ & $25.152,00$ & $286.996,00$ \\
\hline Salários & $23.804,00$ & $23.804,00$ & $23.804,00$ & $23.804,00$ & $23.804,00$ & $23.804,00$ & $23.804,00$ & $23.804,00$ & $23.804,00$ & $23.804,00$ & $23.804,00$ & $25.152,00$ & $286.996,00$ \\
\hline $\begin{array}{l}\text { Despesas } \\
\text { Gerais }\end{array}$ & . & & & & & & & & & & & & \\
\hline Luz & 872,50 & 875,90 & 880,00 & 873,60 & 883,25 & 876,36 & 875,36 & 879,56 & 874,36 & 895,00 & 886,30 & 892,36 & $10.564,55$ \\
\hline Água & 451,00 & 459,56 & 460,25 & 455,95 & 457,25 & 458,90 & 465,23 & 456,75 & 469,36 & 463,64 & 467,25 & 470,56 & $5.535,70$ \\
\hline Telefones & 570,00 & 570,00 & 570,00 & 570,00 & 570,00 & 570,00 & 570,00 & 570,00 & 570,00 & 570,00 & 570,00 & 570,00 & $6.840,00$ \\
\hline Supermercado & $5.145,00$ & $5.300,00$ & $5.458,25$ & $5.250,36$ & $5.356,25$ & $5.195,56$ & $5.322,36$ & $5.158,97$ & $5.100,25$ & $5.475,31$ & $5.400,25$ & $5.600,45$ & $63.763,01$ \\
\hline Internet & 361,00 & 361,00 & 361,00 & 361,00 & 361,00 & 361,00 & 361,00 & 361,00 & 361,00 & 361,00 & 361,00 & 361,00 & $4.332,00$ \\
\hline Educaçăo & $2.261,00$ & 2. 261,00 & $2.261,00$ & 2.261,00 & $2.261,00$ & $2.261,00$ & $2.261,00$ & $2.261,00$ & 2.261,00 & 2.261,00 & 2.261,00 & $2.261,00$ & $27.132,00$ \\
\hline Transportes & $2.150,00$ & $2.500,00$ & $2.350,00$ & $2.450,00$ & $2.360,00$ & $2.650,00$ & $2.435,00$ & $2.156,00$ & $2.268,00$ & $2.365,00$ & $2.450,00$ & $2.550,00$ & $28.684,00$ \\
\hline Vestimentas & $3.265,00$ & $3.125,00$ & $3.210,00$ & $3.150,00$ & $3.300,00$ & $3.036,00$ & $3.098,00$ & $3.110,00$ & $3.136,00$ & 3.185 .00 & $3.144,00$ & $3.250,00$ & $38.009,00$ \\
\hline Saúde & $1.032,50$ & $1.010,35$ & $1.150,25$ & $1.015,69$ & $1.025,36$ & $1.136,36$ & $1.095,00$ & 987,25 & 995,36 & 1.1.100,00 & $1.002,00$ & 958,00 & $12.508,12$ \\
\hline TOTAIS & Janeiro & Fevereiro & Março & Abril & Maio & Junho & Julho & Agosto & Setembro & Outubro & Novembro & Dezembro & TOTAL \\
\hline Rendimentos & $23.804,00$ & $23.804,00$ & $23.804,00$ & $23.804,00$ & $23.804,00$ & $23.804,00$ & $23.804,00$ & $23.804,00$ & $23.804,00$ & $23.804,00$ & $23.804,00$ & $25.152,00$ & $286.996,00$ \\
\hline Gastos & $16.108,00$ & $16.462,81$ & $16.700,75$ & $16.387,60$ & $16.574,11$ & $16.545,18$ & $16.482,95$ & $15.940,53$ & $16.035,33$ & $16.675,95$ & $16.541,80$ & $16.913,37$ & $197.368,38$ \\
\hline Restou & & & & & & & & & & & & & $89.627,62$ \\
\hline
\end{tabular}

Fonte: do acervo dos autores 
DOI: http://dx.doi.org/10.33238/ReBECEM.2019.v.3.n.1.22029

Figura 3: modelo de plano orçamentário 9

\begin{tabular}{|c|c|c|c|c|c|}
\hline \multicolumn{6}{|c|}{ PLANILHA DE ORÇAMENTO DOMÉSTICO- NOV } \\
\hline DESPESAS & PARTICIPANTE 01 & PARTICIPANTE 02 & PARTICIPANTE 03 & PARTICIPANTE 04 & PARTICIPANTE 05 \\
\hline \multicolumn{6}{|l|}{ HABITAÇÃO } \\
\hline Aluguel & & & & 200,00 & \\
\hline IPTU & & & 60,00 & & \\
\hline Energia Elétrica & 30,00 & & 120,00 & & 150,00 \\
\hline Água & 30,00 & & 60,00 & & 80,00 \\
\hline TV por assinatura & & & 10,00 & 10,00 & \\
\hline Telefone & & & & 10,00 & \\
\hline Gás & 79,00 & & 10,00 & 10,00 & \\
\hline \multicolumn{6}{|l|}{ SAÚDE } \\
\hline Plano de saúde & & & 96,00 & & 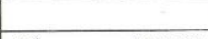 \\
\hline Medicamentos & 18,00 & 80,00 & 60,00 & & 100,00 \\
\hline Dentista & & & 40,00 & & 300,00 \\
\hline Outros & & & 50,00 & & \\
\hline \multicolumn{6}{|l|}{ ALIMENTAÇÃO } \\
\hline Restaurantes & & & & & 200,00 \\
\hline Lanchonetes & 40,00 & 200,00 & 100,00 & 40,00 & 150,00 \\
\hline Supermercado & 200,00 & & 500,00 & 300,00 & \\
\hline Outros & & 150,00 & & & \\
\hline \multicolumn{6}{|l|}{\begin{tabular}{|l|} 
TRANSPORTES \\
\end{tabular}} \\
\hline Ônibus & & & & 115,00 & \\
\hline Van & 220,00 & & & & 200,00 \\
\hline Táxi & & & & & 300,00 \\
\hline Outros & & & 100,00 & & \\
\hline \multicolumn{6}{|l|}{\begin{tabular}{|l} 
AUTOMÓVEL \\
\end{tabular}} \\
\hline \multicolumn{6}{|l|}{ Seguro } \\
\hline Combustivel & & 200,00 & 300,00 & & \\
\hline IPVA & & & 80,00 & & \\
\hline Mecânico & & & 100,00 & & \\
\hline Lavagens & & & & & \\
\hline
\end{tabular}

Fonte: do acervo dos autores

Figura 4: modelo de plano orçamentário

\begin{tabular}{|c|c|c|c|c|}
\hline \multicolumn{5}{|l|}{ PLANILHA ANUAL DE GASTOS DE 2017} \\
\hline DESPESAS & & & & \\
\hline ALIMENTAÇĀO (mercado, padaria) & RS & 5.400 .00 & RS & $6,360,00$ \\
\hline CASA (água, luz, aluguel, gás) & RS & - & RS & $2.760,00$ \\
\hline OUTROS GASTOS DA CASA (internet, telefone, tv a cabo, mercado para limpeza) & RS & - & RS & 480,00 \\
\hline EDUCAÇĀO (mensalidade, xerox, impressāo, material escolar, palestra) & RS & 6.000 .00 & RS & 6.726 .00 \\
\hline VESTUARIO (roupas e calçados) & RS & $7.800,00$ & RS & 900,00 \\
\hline LAZER (lanchonete, bar, casa notuma, churrasco, cinema, viagens) & RS & $1.500,00$ & RS & $3.000,00$ \\
\hline TRANSPORTE (combustivel, T. Coletivo, estacionamento, manutençăo do veiculo) & RS & $4.560,00$ & RS & $1.500,00$ \\
\hline SAÚDE (dentista, consultas, farmacia, plano de saude, rémedios) & RS & $2.300,00$ & RS & $2.000,00$ \\
\hline GASTOS ESPORADICOS (credito de celular, moveis, utensilios domesticos, presentes) & RS & $1.000,00$ & RS & 930,00 \\
\hline GASTOS ANUAL DE CADA & RS & $28.560,00$ & RS & 24.656 .00 \\
\hline MEDIA MENSAL DE CADA & RS & $2.380,00$ & RS & $2.054,66$ \\
\hline MEEDIA TOTAL & RS & & & $26.608,00$ \\
\hline SOMA TOTAL & RS & & & $53.216,00$ \\
\hline
\end{tabular}

Fonte: do acervo dos autores

Alguns dos grupos optaram pela formulação individual dos planos para uma junção final do todo, como pode ser visto na figura 3, outros grupos pensaram em planos para respostas coletivas no interior do grupo, como observado na figura 2 e 4 . Em certo

${ }^{9} \mathrm{O}$ nome dos alunos em todas as imagens foram suprimidos no intuito de preservar a identidade de cada um. 
DOI: http://dx.doi.org/10.33238/ReBECEM.2019.v.3.n.1.22029

sentido, isso mostra a flexibilização que a modelagem permite no que tange aos múltiplos caminhos e respostas às atividades, além da dinamicidade evidente no interior dos próprios grupos.

\begin{abstract}
Em contextos de sala de aula, a qualidade de comunicação depende, em grande medida, da forma como as situações de ensino e aprendizagem são organizadas, da maior ou menor necessidade de interações para subsidiar ações do professor, dos alunos e da relação que se estabelece entre esses e com a comunidade. Nesse sentido, podemos considerar que a qualidade das interações está relacionada com as atividades desenvolvidas pelos indivíduos em diferentes circunstâncias (ALMEIDA, 2012, p. 32).
\end{abstract}

Nesse mesmo contexto, a socialização dos modelos elaborados se mostrou particularmente enriquecedora, pois os alunos puderam depreender reflexões em relação às estratégias utilizadas por cada grupo, bem como, trocaram experiências sobre como construir diferentes modelos financeiros que melhor se ajustava para cada grupo, considerando as especificidades.

Outro momento importante diz dos conteúdos utilizados para resolução das atividades. Uma vez que, a proposta acontece no contexto de uma disciplina de Estatística, os grupos em sua totalidade utilizaram de estratégias, vistas no decorrer da disciplina, para "atacar" a problemática, como por exemplo o cálculo de médias, moda, mediana, variância, coeficientes de assimetria, desvio padrão, construção gráfica e interpretações de resultados como observado na figura 05 e 06. 
DOI: http://dx.doi.org/10.33238/ReBECEM.2019.v.3.n.1.22029

Figura 5: modelo de plano orçamentário

Visto que, com o total de gastos de cada aluno foram feitos cálculos para identificar a assimetria, desvio padrăo, mediana, média, moda e variância, no qual foram utilizados os gastos mensais de cada um. Logo abaixo, estão os cálculos que auxiliaram para chegar aos resultadios que estäo dispostos no quadro 2 .

Média:

$1357,87+2375,77+1708,56+987,86+3647,87 / 5=2015,59$

Mediana

$5+1 / 2=3 \quad 3^{\circ}$ termo $=1708,56$

Variância

$(1357,87-2015,59) 2+(2375,77-2015,59) 2+(1708,56-2015,59) 2+(987,86-$ $2015,59) 2+(3647,87-2015,59) 2 / 5=(-657,72) 2+(360,78) 2+(-307,03) 2+(-$ $1027,73) 2+(1632,28) 2 / 5=$

$1315,44+721,56+614,06+2055,46+3264,56 / 5=$

$7971,08 / 5=1594,22$

Assimetria

$3(2015,59-1708,56) / 5=3(307,03) / 5=187,22$

Desvio padrão

Raiz de $1594,22=39,93$

Quadro 2: Cálculos com valores mensais.

\begin{tabular}{|c|c|c|}
\hline & Cálculos & \\
\hline Alunos & Valor Total & \\
\hline $\mathrm{x}$ & & $\mathrm{R} \$ 1.357,87$ \\
\hline y & & $\mathrm{R} \$ 2.375,77$ \\
\hline$z$ & & $\mathrm{R} \$ 1.708,56$ \\
\hline k & & $\mathrm{R} \$ 987,86$ \\
\hline I & & $\mathrm{R} \$ 3.647,87$ \\
\hline Moda & & Amodal \\
\hline Média & & 2015,59 \\
\hline Mediana & & 1708,56 \\
\hline Variância & & 1594,22 \\
\hline Assimetria & & 187,22 \\
\hline Desvio Padrão & & 39,93 \\
\hline
\end{tabular}

Fonte: do acervo dos autores
Figura 6: modelo de plano orçamentário

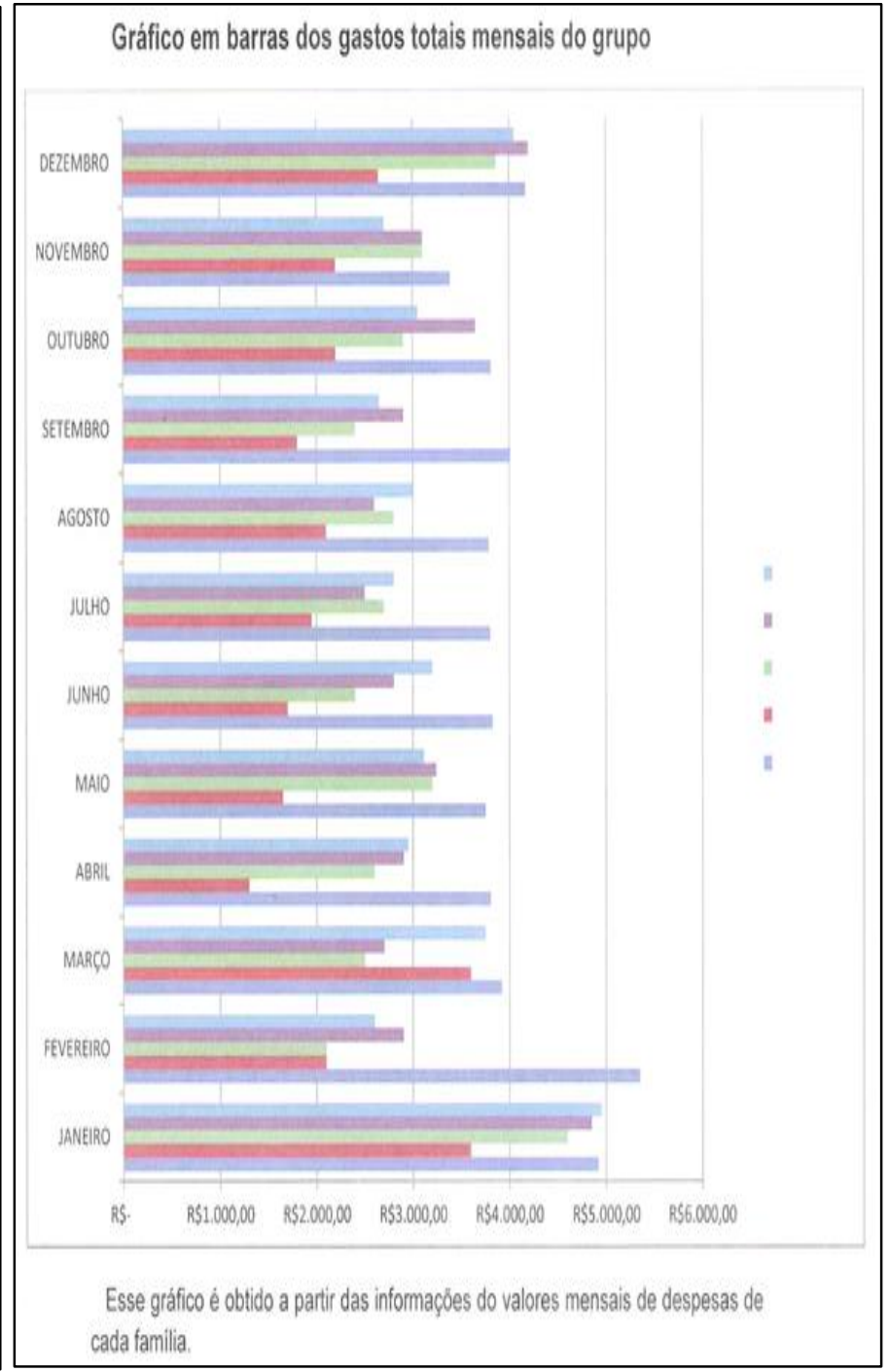

Fonte: do acervo dos autores

Vale ressaltar que os grupos acionaram o professor no intuito de confirmar se determinado cálculo fazia sentido no contexto do exercício. Nesse momento, pudemos resgatar alguns conceitos de estatística inferencial, estatística descritiva, do cálculo da variância, desvio padrão e coeficiente de variação, já vistos no decorrer da disciplina, porém, considerando a particularidade de cada grupo. Para além disso, observamos na figura 5 a complementaridade dos resultados manifestada na forma gráfica. A opção em lançar luz a essa forma de representação partiu diretamente dos alunos, pois consideravam um meio de expressar seus resultados de uma forma mais visual, assumindo que os gráficos permitem, entre outros aspectos, a visualização e a comparação direta entre diferentes variáveis. 
DOI: http://dx.doi.org/10.33238/ReBECEM.2019.v.3.n.1.22029

Outro aspecto concerne à contextualização das atividades na relação com os conteúdos. Alguns grupos buscaram em outras fontes, além daquela disponibilizada para eles, como já mencionado. Essas consultas em fontes variadas, tornaram-se facilitadoras no processo de resolução, por exemplo, alguns grupos investigaram o comportamento do salário mínimo no decorrer de 10 anos (passado) a partir dos dados coletados, e de cálculos efetuados, estabeleceram taxas as quais utilizaram para as previsões para daqui 10 anos (futuro), como representado na figura 07.

Figura 7: modelo de plano orçamentário

\begin{tabular}{|c|c|c|c|c|c|c|c|}
\hline \multicolumn{2}{|c|}{ Quedio 6: Projecsso da salsris minimo em 10 anos } & \multicolumn{6}{|c|}{ Quadro 7 : Projecso de gastos influenciadm pelo salanio minimo } \\
\hline \multicolumn{2}{|r|}{ 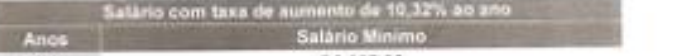 } & \multicolumn{6}{|c|}{ 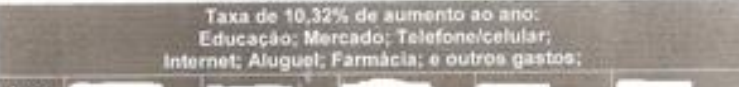 } \\
\hline 2018 & RS $1.033,70$ & Anos: & 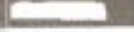 & 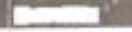 & $=$ & 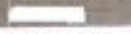 & \\
\hline 2010 & Fos $1.140,38$ & 2017 & Rs 857,87 & RS $1,331,77$ & RS $1.327,87$ & R\$ 987,86 & RS $1.907,87$ \\
\hline 2020 & RS 1.25800 & 2018 & RS 946,40 & Rs $1,469,21$ & RS 1,464,91 & RS 1.089 .81 & R\$ $2.104,70$ \\
\hline 2021 & $\begin{array}{r}\text { RS } 1.387,89 \\
\text { ? } \quad \text { Rs } 1.531,13\end{array}$ & 2019 & Rs $1.044,07$ & RS $1,620,83$ & R\& $1.616,08$ & Rs $1.202,28$ & R\$ 2.321 .97 \\
\hline 2023 & Rs 1.609 .14 & 2020 & RS $1.151,82$ & R\$ $1,788,10$ & RS $1,782,85$ & R\$ $1.326,35$ & RS $2.501,60$ \\
\hline 2024 & Rs $1,563,40$ & 2021 & RS $1.270,69$ & Rs $1.972,63$ & RS $1.966,86$ & RS 1.463 .23 & R5 2825.96 \\
\hline 2025 & R\$ 2055,77 & 2022 & RS $1,401,83$ & Rs 2.176 .21 & R\$ $2.169, \$ 4$ & RS 1.814 .24 & RS $3,117,60$ \\
\hline 2096 & $\begin{array}{l}\text { RS } 2.257 .92 \\
\text { He. } 2571.97\end{array}$ & 2023 & Rs $1.846,49$ & RS $2.400,70$ & RS 2393,76 & RS $1,780,83$ & RS $3,439,33$ \\
\hline $\begin{array}{l}20027 \\
\text { Fonde Dace }\end{array}$ & Fonda Dados ca perqusa & 2024 & Rs $1.708,09$ & RS 2.648 .55 & Rs $2.640,80$ & RS 1.964 .61 & R\$ $3,794,27$. \\
\hline \multirow{3}{*}{\multicolumn{2}{|c|}{ 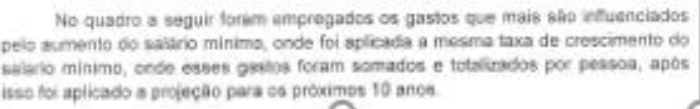 }} & 2025 & Rs $1.882,16$ & R5 $2.921,88$ & RS 2.913,33 & RS 2167,36 & RS 4,185,84 \\
\hline & & 2026 & RS 2.076 .40 & Rs $3.223,42$ & RS $32.213,98$ & R\$2.391,03 & RS $4.617,82$ \\
\hline & & $\begin{array}{l}2027 \\
\text { Fonte: }\end{array}$ & $\begin{array}{l}\text { RS } 2.290 .68 \\
\text { Dados da pese }\end{array}$ & $\begin{array}{l}\text { RS } 3.556,08 \\
\text { uisa }\end{array}$ & RS $3,545,67$ & R\$ $2.637,78$ & RS $5.094,38$ \\
\hline
\end{tabular}

Fonte: do acervo dos autores

Ressaltamos, porém, que nem todos os membros dos grupos mostraram interesse no desenvolvimento da atividade. Isso pode ser entendido como uma característica particular dos discentes, ou ainda uma má organização no interior dos grupos ou distribuição de tarefas. Essa postura pode ser um reflexo da mudança no contexto da sala de aula, ou seja, o professor deixa de exercer o papel de transmissor do conhecimento, comum nas posturas tradicionalistas e transfere ao aluno a responsabilidade pela construção do conhecimento, o que nem sempre é bem recebido pelos discentes. Portanto, essa postura indiferente à atividade pode dizer da pouca aproximação dos acadêmicos com esse tipo de prática em que são provocados à investigação e à construção do seu próprio conhecimento.

Mesmo frente a isso, optamos por não interferir no aspecto concernente à participação dos alunos no interior dos grupos, de tal modo que as decisões deveriam ser negociadas e tomadas pela totalidade do grupo. Não consideramos que o número de alunos é um aspecto preponderante ou rígido, visto que, alguns grupos constituídos por um número elevado de alunos apresentaram como produto final trabalhos relevantes para o contexto da disciplina, enquanto outros grupos com quantidades reduzidas de alunos, 
DOI: http://dx.doi.org/10.33238/ReBECEM.2019.v.3.n.1.22029

apresentaram produtos finais que se descaracterizaram de uma atividade de modelagem, mesmo sob orientações constantes do docente.

Além disso, entendemos que o trabalho em grupo permite reflexões que talvez em um trabalho individual não se concretize, visto que, os alunos têm a possibilidade de, a partir da individualidade, discutir conceitos e construir novos conhecimentos na coletividade estabelecida no interior dos grupos.

Este processo de construção, por se manifestar na e pela interação social, adquire "visibilidade". Esta "visibilidade", por sua vez, promove um alargamento da capacidade cognitiva individual, na medida em que propiciou a realização em conjunto daquilo que sozinho não seria realizado (DAVIS; SILVA; ESPÓSITO, 1989, p. 52).

De acordo com os autores supracitados, há possibilidade de romper com a hierarquia absolutista que em vez de distinguir professor e aluno, apenas os separa e segrega. Em certo sentido, essas colocações lançam luz sobre nossa visão para os grupos em uma atividade de modelagem, já que é entendido pela própria comunidade de modelagem que a tendência por si só tem como característica marcante a promoção do trabalho em grupo e a construção do conhecimento a partir desse trabalho coletivo.

\section{Reflexões sobre a experiência vivida}

Desenvolver a atividade como proposta da disciplina do curso de pós-graduação, sob o contexto de uma disciplina de graduação, obviamente, contribuiu para o encorajamento em implementar novas práticas no que tange à modelagem matemática, visando dessa maneira, superar as inseguranças que emergem da própria prática e que não se mostram nos estudos teóricos. Para tanto, o estabelecimento de uma interrogação o que se mostra dos grupos de alunos em uma atividade de Modelagem Matemática? se revelou fundamentalmente importante, pois, sugere um olhar para outros aspectos além dos apresentados.

Estabelecer novas práticas em sala de aula, como aquelas decorrentes do uso da Modelagem Matemática permite superar a estreiteza do ensino tradicional, buscando um ensino dinâmico e significativo para o aluno.

O esforço no planejamento da atividade, em conjunto com o primeiro autor deste relato, permitiu reflexões de cunho teórico, ou seja, há a preocupação em não afastar a atividade quando planejada pelo docente - nosso caso - da realidade dos alunos. Além 
DOI: http://dx.doi.org/10.33238/ReBECEM.2019.v.3.n.1.22029

disso, a própria atividade permite lançar olhar para elementos distintos a serem investigados, nesse trabalho.

Revelaram-se aspectos que dizem, da abordagem do conteúdo, ou seja, aqueles necessários para "atacar" a problemática em questão, o que pressupõe o "acesso" a conhecimentos já construídos ou ainda a construção de novos conteúdos. Revela ainda, das estratégias para as resoluções e coleta dos dados, ou seja, se isso seria feito na coletividade do grupo ou na individualidade de cada membro do grupo.

Destacamos também a versatilidade metodológica da Modelagem, pois vislumbramos nela uma possibilidade para a mudança da postura comumente adotada em sala, proporcionando aos alunos a dinamicidade sem deixar de dar conta dosconteúdos impostos pelas ementas, superando um mero cumprimento, ainda que isso não deixe de ocorrer. A articulação da disciplina em si com a formação acadêmica dos envolvidos também merece destaque, já que no papel de docente se fez necessário aprofundar os conhecimentos sobre as particularidades da profissão - Gestor Financeiro.

Ressaltamos ainda o envolvimento dos alunos, pois a atividade foi desenvolvida no final do ano letivo, ou seja, além dos trabalhos acadêmicos os alunos estavam próximos a "semana de provas" o que poderia ter influenciado na participação deles. No entanto, entendemos que a mudança no contexto da sala de aula, provocou nos acadêmicos interesse, além do instinto investigador, já que estes entenderam, a partir do diálogo no interior dos grupos, que a atividade poderia focar uma situação real em que eles, por exemplo, teriam que efetuar previsões orçamentarias para uma determinada empresa.

O trabalho em grupo, é um elemento que merece atenção, considerando que permite reflexões sob diferentes aspectos, como por exemplo o diálogo interno no intuito de superar divergências, a própria dificuldade em desenvolver atividades em grupo, a segurança no que tange o desenvolvimento de conteúdos matemáticos/estatísticos.

Em relação ao aspecto que denominamos de diálogo interno, revelou-se que os alunos transitam por dois momentos distintos: um em que se sentem confortáveis para expor as ideias junto aos colegas do grupo, apontando possibilidades para a construção dos modelos ou sugestões de como atacar determinada problemática, isso revela que os alunos passam a ser responsáveis pela construção do conhecimento, pois buscam por si só diferentes alternativas para o problema em questão; outro aspecto também merece atenção, na contramão do diálogo fluído no interior dos grupos, no qual emerge a 


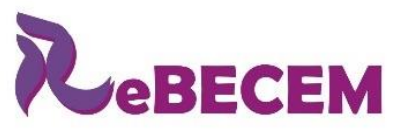

DOI: http://dx.doi.org/10.33238/ReBECEM.2019.v.3.n.1.22029

resistência de alguns alunos no desenvolvimento de atividades que exigem essa característica, talvez pelo fato de alguns alunos serem mais introvertidos que outros. Foi possível notar que alguns alunos se mostraram menos participativos. No entanto, é aceitável que atividades que exijam a participação de um grupo tenham lideranças, porém é importante observar e motivar os integrantes de forma que em um momento ou outro se mostrem responsáveis pelo desenvolvimento da atividade, fato esse que pode ser notado pelos modelos construídos, considerando que esses modelos traziam dados de membro a membro do grupo ou da totalidade do grupo ou uma combinação entre eles. Portanto, entendemos, assim, que ao menos no que concerne o levantamento dos dados, todos de maneira mais ou menos engajados participaram da atividade.

Revelou-se ainda, no contexto dos grupos, elementos que permitem reflexão em relação ao tratamento com os conteúdos matemáticos, elementos esses que dizem da discussão sobre como desenvolver matematicamente os modelos, como apresentar os dados coletados, como tratar desses dados utilizando elementos estatísticos. Pudemos observar que os alunos buscaram no interior do grupo sanar dúvidas uns dos outros, recorrendo ao professor somente em casos que buscavam verificar se os procedimentos que desenvolviam estavam alinhados ao modelo ou não. Nesse contexto, verificaram cálculos uns dos outros e revisaram os conteúdos quando necessário. Entendemos que as atividades em grupo possibilitaram um diálogo mais aberto no que se refere a abordagem dos conteúdos entre os alunos, pois o tratamento entre os membros se deu de modo menos formal, sem intenções didáticas explícitas para presentes para a construção do conhecimento.

Considerando o apresentado defendemos que vivenciar as atividades de modelagem, ou seja, exercitar a implementação da prática é fundamentalmente importante, pois assim, estabelecemos reflexões no que concerne a diferentes aspectos, inclusive sobre os teóricos. Tais reflexões abrem margem para discussões em outros âmbitos, seja acadêmico, seja no contexto da Educação Básica, proporcionando a disseminação da Modelagem Matemática enquanto uma prática efetiva.

No que concerne aos grupos de trabalhos nas atividades de Modelagem, entendemos que as interações entre os sujeitos permitirá muitas vezes compreensões que superam as colocações feitas pelo próprio docente, considerando que em diversos momentos as reflexões, diálogos e o exercício de exposição de ideias no interior dos grupos se revelava de maneira espontânea, ou seja, sem uma relação hierárquica, o que 
DOI: http://dx.doi.org/10.33238/ReBECEM.2019.v.3.n.1.22029

contribui para construção do conhecimento matemático no contexto das atividades de Modelagem Matemática.

\section{Referências}

ALMEIDA, L. W. de. Modelagem Matemática na educação básica. Lourdes Werle de Almeida, Karina Pessôa da Silva, Rodolfo Eduardo Vertuan. São Paulo: Contexto, 2012.

BARBOSA, J. C. Modelagem Matemática: O que é? Por que? Como? Veritati, n. 4, p. 73-80, 2004.

BARBOSA, J. Cerqueira. Modelagem Matemática e os professores: a questão da formação. Bolema, Rio Claro, n. 15, p. 5-23, 2001.

BERNADO, E. da S. Um olhar sobre a formação continuada de professores em escolas organizadas no regime de ensino em ciclo(s). Texto apresentado na Reunião Anual da ANPED -GT 08. Caxambu, MG, 2004.

BRANDT, C. F.; BURAK, D. Burak; KLÜBER, T. E. Modelagem Matemática: uma perspectiva para a Educação Básica. Ponta Grossa, Editora UEPG, 2010.

BULGRAEN; V. C. O papel do professor e a sua mediação nos processos de elaboração do conhecimento.Revista Conteúdo, Capivari, v.1, n. 4, ago/dez 2010.

DAVIS, C.; SILVA, M. A. S. S. E. Papel e valores das interações sociais em sala de aula. Cad. Pesq., São Paulo, v. 71, p. 49-54, nov. 1989.

GARCÍA, C. M. Formação de professores: para uma mudança educativa. Portugal: Porto Editora, 1999.

KLÜBER, T. E. Formação de professores em Modelagem Matemática na Educação Matemática Brasileira: Questões emergentes. Educere et Educare, Cascavel, v. 12, n. 24, jan./abr. 2017.

KLÜBER, T. E.; BURAK, D. Concepções de modelagem matemática: contribuições teóricas. Educação, Matemática, Pesquisa, São Paulo, v. 10, n. 1, p. 17-34, 2008.

LOUREIRO, D. Z. Abordagem do conteúdo matemático em Modelagem Matemática na Educação Matemática: um metaestudo das produções didático pedagógicas do Programa de Desenvolvimento Educacional - PDE/PR. 2016. Dissertação (Mestrado em Educação) Universidade Estadual do Oeste do Paraná, Cascavel, 2016.

Recebido em: 30 de março de 2019.

Aceito em: 30 de abril de 2019. 